\title{
Erratum to: Medication therapy for attention deficit/hyperactivity disorder is associated with lower risk of fracture: a retrospective cohort study
}

\author{
B. A. Perry ${ }^{1}$ K. R. Archer ${ }^{2,3} \cdot$ Y. Song ${ }^{4} \cdot$ Y. Ma ${ }^{5} \cdot$ J. K. Green ${ }^{6,7}$. \\ F. Elefteriou ${ }^{5,8,9} \cdot$ K. M. Dahir ${ }^{1}$
}

Published online: 16 March 2016

(C) International Osteoporosis Foundation and National Osteoporosis Foundation 2016

Erratum to: Osteoporos Int

DOI: $10.1007 / \mathbf{s 0 0 1 9 8 - 0 1 6 - 3 5 4 7 - 1 ~}$

Owing to a misunderstanding, the authors' affiliations were rendered incorrectly. Their correct affiliations are given here.

The online version of the original article can be found at http://dx.doi.org/ 10.1007/s00198-016-3547-1.

K. M. Dahir

kathryn.dahir@vanderbilt.edu

1 Department of Medicine, Division of Diabetes, Endocrinology, and Metabolism, Vanderbilt University, 1215 21st Avenue South, 8210 Medical Center East, South Tower, Nashville, TN 37232, USA

2 Department of Orthopaedic Surgery, Vanderbilt University, Nashville, TN, USA

3 Department of Physical Medicine and Rehabilitation, Vanderbilt University, Nashville, TN, USA
4 Department of Biostatistics, School of Medicine, Vanderbilt University, Nashville, TN, USA

5 Department of Medicine, Division of Clinical Pharmacology, Vanderbilt University, Nashville, TN, USA

6 Department of Medicine, Vanderbilt University, Nashville, TN, USA

7 Department of Pediatrics, Vanderbilt University, Nashville, TN, USA

8 Department of Pharmacology, Vanderbilt University, Nashville, TN, USA

9 Department of Cancer Biology, Vanderbilt University, Nashville, TN, USA 